\title{
Screening for Changes on Iris germanica L. Rhizomes Following Inoculation with Arbuscular Mycorrhiza Using Fourier Transform Infrared Spectroscopy
}

\author{
Ioana Crișan $^{1}\left(\mathbb{D}\right.$, Roxana Vidican ${ }^{1, *}$, Loredana Olar $^{2}$, Vlad Stoian $^{1} \mathbb{D}$, Adriana Morea ${ }^{1}$ and \\ Răzvan Ștefan $2,3, *$ \\ 1 Faculty of Agriculture, University of Agricultural Sciences and Veterinary Medicine, Manastur Street No. \\ 3-5, 400372 Cluj-Napoca, Romania; ioana.crisan@usamvcluj.ro (I.C.); vlad.stoian@usamvcluj.ro (V.S.); \\ adriana.morea@usamvcluj.ro (A.M.) \\ 2 Faculty of Veterinary Medicine, University of Agricultural Sciences and Veterinary Medicine, Manastur \\ Street No. 3-5, 400372 Cluj-Napoca, Romania; loredana.olar@usamvcluj.ro \\ 3 Department of Biophysics, Life Sciences Institute "King Michael I of Romania", Manastur Street No. 3-5, \\ 400372 Cluj-Napoca, Romania \\ * Correspondence: roxana.vidican@usamvcluj.ro (R.V.); rstefan@usamvcluj.ro (R.S..); \\ Tel.: +40-264-596-384 (int. 174) (R.V.)
}

Received: 3 November 2019; Accepted: 26 November 2019; Published: 28 November 2019

\begin{abstract}
Iris germanica L. is an ornamental and medicinal plant used since ancient times for their rhizomes, still utilized today to obtain orris butter highly valued in perfumery. Iris germanica presents special root adaptations, which confers certain tolerance to water and salt stress, making it a good option in the context of the current climate trend. Aim of this study was to prospect the potential for biofortification of rhizomes using commercial arbuscular mycorrhizae (AM) application in field conditions for six Iris germanica cultivars. Plants presented Paris-type AM colonization. Rhizome samples collected after nine months from treatment and maturated, presented FT-IR (fourier transform infrared spectroscopy) spectra variation between experimental variants. Presence of the main metabolites in rhizome could be confirmed based on literature. Screening focused on two rhizome quality markers: carbohydrates, which influence plant development, and fatty acids, which are extractable from rhizome. Results suggest potential to enhance their accumulation in certain cultivars, such as 'Pinafore Pink' following AM application.
\end{abstract}

Keywords: Glomeromycota; biotroph; plant metabolites; quality marker; spectroscopy

\section{Introduction}

Iris germanica L. is a widespread ornamental plant [1] and has been used since ancient times in Europe for their rhizomes, currently highly valued in perfumery. Dry rhizome pieces are used as a spice, while rhizome extracts find application in the cosmetic industry and food industry as flavoring agents or in the production of alcoholic beverages such as gin [2]. Commonly cultivated are Iris germanica L. var. florentina and Iris pallida Lam [3,4] but almost any old garden bearded iris can be processed for this purpose with varying results [5]. Important Iris sp. crops are found in Italy, Morocco, China and India [3]. Iris sp. rhizomes harvested are either decorticated and slowly dried according to traditional method up to several years or sliced and subjected to biotechnological process for a fast-induced maturation $[2,5,6]$. Next, "aged" orris is milled and steam distillated to obtain orris butter rich in irone and myristic acid [3,4,7,8] sold at $14640 €$ for $1 \mathrm{~kg}$ [9].

Iris germanica is native to eastern Mediterranean region [2], and as adaptation to drought-prone habitats Iris germanica roots evolved multiseriate exodermis (MEX) - a trait within a suite of 
specializations which confers certain tolerance both to water and salt stress [10]. Since these are main challenges plants face within the current climate trend [11], ability to cope with such factors make this perennial a suitable option for smart landscaping as well as attractive niche crop. In addition, Iris germanica is a model plant for root studies [10], yet interaction with root fungal symbiotic colonizers and the outcome of this partnership has not been given much attention yet.

Arbuscular mycorrhizae (AM) is a symbiosis between plants roots and fungi from phylum Glomeromycota known for improving nutrition of plants, particularly in phosphorus [12]. Since phosphorus is required for biosynthesis of plant metabolites, its availability plays a crucial role [13]. Thus, common responses to AM may occur in relation with different plant metabolites, which are connected to general P-controlled pathways [14]. The positive influence of inoculation with arbuscular mycorrhizal fungi on certain plant metabolites $[15,16]$ indicates that their application could be used as a strategy of crop biofortification [17] and many researches in the last decade aimed to identify specific effects AMF (arbuscular mycorrhizal fungi) can have on phytochemicals of economic interest [15,16,18-20]. Remarkably, many metabolite classes are affected by symbiosis with arbuscular mycorrhiza fungi species, and systemic responses have been found in various species from diverse plant families [14].

As a result, potential of AM to enhance phytochemical content attracted particular interest due to positive economic implications this might have, with wide range of researches conducted mostly in controlled environment. Review of over 40 representative studies from the last two decades, across ten botanic families in relation with changes in different metabolites from aromatic and medicinal plants due to AMF application, indicate that $37 \%$ of these studies were performed on plants from the Lamiaceae family. Across all ten botanic families, in over half of cases (65\%) inoculated species were from two common Glomeraceae genera. On first place as most frequently used is genus Rhizophagus (45\%) with Rhizophagus irregularis as the main species found across studies, followed by genus Funneliformis (20\%) with Funneliformis mosseae as the most frequent species [21].

Fourier transform infrared spectroscopy (FT-IR) is a sensitive tool allowing measurement based on vibration of molecular bounds [22], which have specific frequency corresponding to an energy level. Spectra obtained are a graphical representation of absorption in units (A) versus IR frequency in terms of wavenumber $\left(\mathrm{cm}^{-1}\right)$. Bands in a spectrum are characterized by a wavenumber at which absorption occurs, corresponding to chemical bonds and the intensity of absorption, proportional to the amount of substance from sample [23]. Spectra are highly reproducible and informative representing signature of the overall chemical composition from a sample. FT-IR can be used both for identification purposes and for quantitative and qualitative analysis. In life sciences has been proven useful in analysis of microbial bioprocesses [22] as well as plant composition [24]. However, to the authors' knowledge this method has not been utilized yet to screen for changes in plant following AM application.

Two important constituents of the Iris germanica rhizome: starch and myristic acid [25] were selected as quality markers and their spectral fingerprint was analyzed in this study. Irones are also valuable compounds but are not secondary metabolites of plant since they are absent from fresh rhizomes, instead they derive post-harvest from precursors [3] and are a marker for orris butter quality [2].

The aim of this study was to screen using FT-IR for variations in phytochemical content of rhizomes due to AM inoculation and cultivar for Iris germanica grown in field conditions.

To achieve this, three objectives were defined:

- Test potential of FT-IR to screen for variation in rhizome composition;

- Identify if rhizome quality markers display response associated with treatments;

- Define fingerprint ranges that could be used to confirm presence of main metabolites. 


\section{Materials and Methods}

\subsection{Location and Conditions}

The experiment was established in Botanical Garden UASVM Cluj-Napoca Romania, on October 2016. Previous plant grown on plot was Dahlia hybrida. Soil characteristics of the experimental plot for topsoil (depth of 0-20 cm) were determined at an authorized pedological laboratory from Cluj-Napoca. Analysis is presented in Table 1, results indicated clay-loam soil type with low humus level, but good nitrogen, phosphorus and potassiumsupply according to thresholds from literature [26].

Table 1. Soil characteristics of the experimental plot $[27,28]$.

\begin{tabular}{ccc}
\hline Parameter & Method & Results \\
\hline $\mathrm{pH}$ & Potentiometric & 6.72 \\
\hline Humus & Walkley-Black & $1.35 \%$ \\
\hline Nitrogen & Kjeldahl & $0.461 \%$ \\
\hline Phosphorus & Colorimetric & $68 \mathrm{ppm}$ \\
\hline Potassium & Flame photometry & $312 \mathrm{ppm}$ \\
\hline Basic cation saturation & Kappen & $20.96 \mathrm{me} / 100 \mathrm{~g}$ \\
\hline Hydrolytic acidity & Extraction & $1.92 \mathrm{me} / 100 \mathrm{~g}$ \\
\hline Base saturation $(\mathrm{V})$ & Calculation & 92 \\
\hline Granulometric & Kacinscki & $\begin{array}{c}\text { Coarse sand 14.42, fine sand 25.08, } \\
\text { silt I 7.95, silt II 13.65, clay 38.90 }\end{array}$
\end{tabular}

Climatic data for interval between October 2016-July 2017, corresponding to interval between planting and rhizome harvesting can be seen in Figure 1. During overwintering of the plants in field, temperatures reached as low as $-18{ }^{\circ} \mathrm{C}$ in January and as high as $34{ }^{\circ} \mathrm{C}$ in July at the end of the experiment. Highest precipitation levels in descending order, were registered during months of October-prior and during planting-and in April when plants were in leaf elongation phenophase. Water availability at the time of planting ensured rooting of plants in autumn before winter dormancy and favorable growth conditions were met again in spring at when plants entered in vegetation.

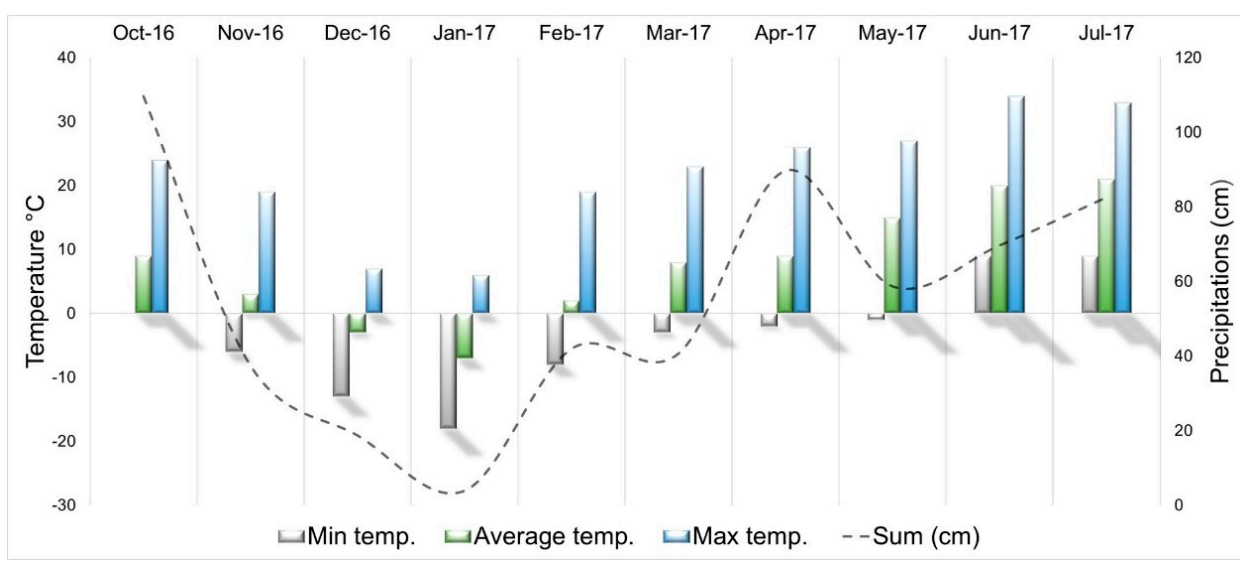

Figure 1. Climatic data for interval between planting of Iris germanica and rhizome harvesting [29].

\subsection{Treatments}

The experiment was organized according to bifactorial design: Factor A-Iris germanica cultivars with six levels: $\mathrm{a}_{1}=$ 'Black Dragon' (black flowers), $\mathrm{a}_{2}=$ 'Blue Rhythm' (blue flowers), $\mathrm{a}_{3}=$ 'Sultan's Palace' (red flowers), $\mathrm{a}_{4}=$ 'Lime Fizz' (yellow flowers), $\mathrm{a}_{5}=$ 'Pinafore Pink' (pink flowers) and $\mathrm{a}_{6}=$ 
'Pure as The' (white flowers) and Factor B-the treatment applied with two levels: $b_{1}=$ non-inoculated at planting (AM- and $\mathrm{b}_{2}=$ inoculated at planting with 13 grams/rhizome commercial AM products $(\mathrm{AM}+)$.

Two products licensed by Royal Horticultural Society: "Bulb starter" and "After Plant" with root grow ${ }^{\mathrm{TM}}$ mycorrhizal fungi and destined for outdoors and garden use, produced by company PlantWorks Ltd. United Kingdom [30] were mixed and applied together. One is specially designed for geophytes while other is suitable for perennials in general. Both contained propagules of five AMF species: Funneliformis mosseae, Funneliformis geosporus, Claroideoglomus claroideum, Rhizoglomus intraradices and Rhizoglomus microaggregatum, in an organo-mineral carrier. The carriers according to the label are represented by vermiculite for the first product and PAS100 certified recycled green compost for the second one, to which are added selected essential trace elements for supporting the establishment of AM symbiose in field. Plant material imported from Holland was purchased from company Anthesis International Bucharest. Prior to planting, all rhizomes had roots and leaves trimmed, were washed with chlorine solution, rinsed and planted with "hump" facing south. Between the non-inoculated and inoculated rows were ensured $7 \mathrm{~m}$ distance. From a combination of the two factors resulted 12 experimental variants, which were organized in randomized blocks with three replicates. In total were planted 108 rhizomes (Figure 2).

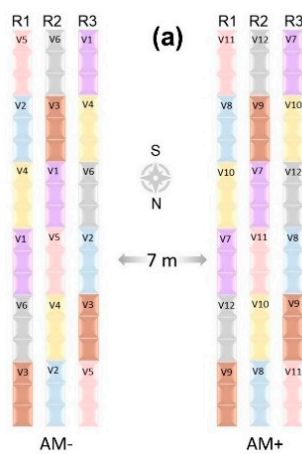

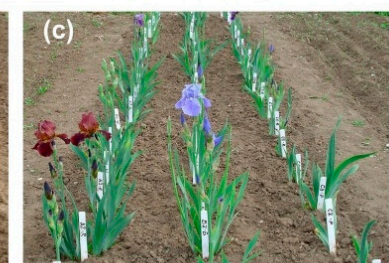
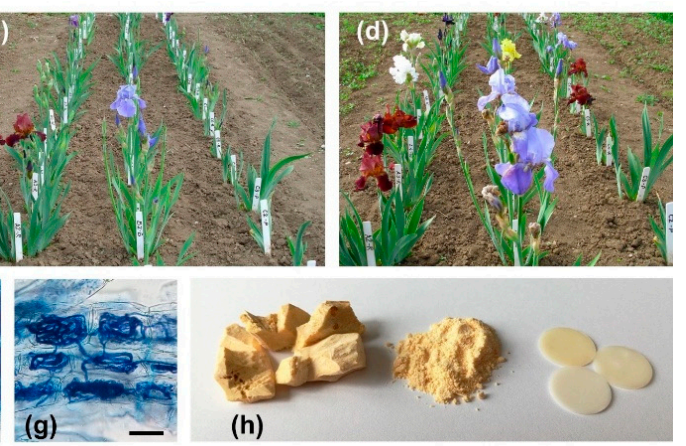

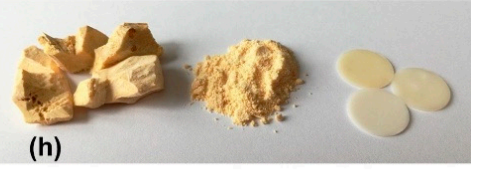

Figure 2. Experiment aspects: (a) planting plan, (b,c,d) stages in plant development, (e) rhizome, (f,g) arbuscular mycorrhizae (AM) Paris-morphotype inside Iris germanica stained roots, bar $=50 \mu \mathrm{m}$ and (h) dry rhizome turned into pellets.

\subsection{Assays}

\subsubsection{AM Analysis}

At post-anthesis, on June 2017 and after 8 months from planting the rhizomes, root samples were collected and prepared for microscopy using ink-vinegar staining technique [31] followed by AM colonization evaluation through the Trouvelot method [32]. Indicators were obtained using Mycocalc [33]. Pearson correlogram for AM colonization parameters for both sets of plants was obtained with Past 3 [34], and are presented in Figure 3 


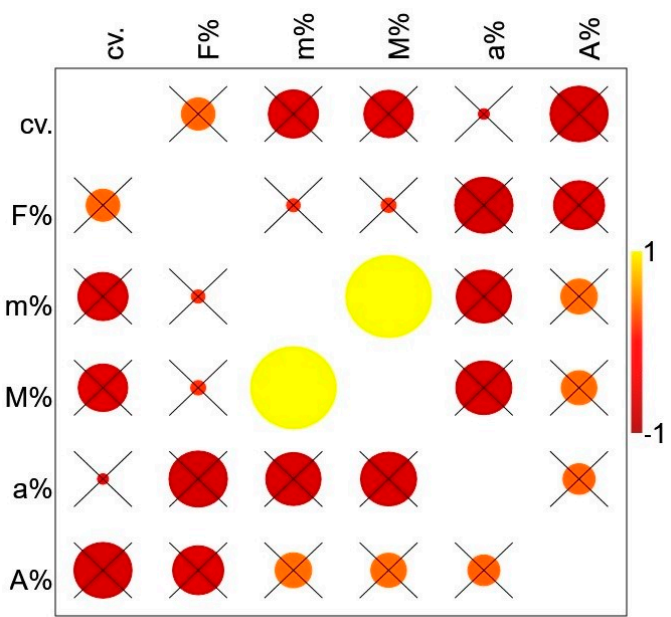

(a)

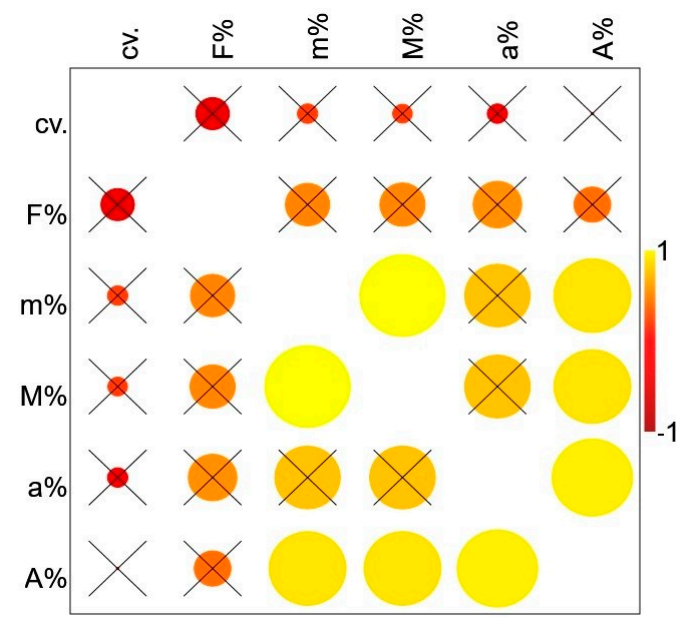

(b)

Figure 3. Correlograms for colonization parameters in two sets of Iris germanica plants: (a) non-inoculated (AM-) and (b) AM inoculated (AM+) after 8 months in field, where: $\mathrm{cv}$-cultivar gradient, $\mathrm{F} \%$ - AM frequency, $\mathrm{m} \%$ - AM intensity in root fragments, $\mathrm{M} \%-\mathrm{AM}$ intensity in root system, $\mathrm{a} \%$-arbuscules abundance in mycorrhizal parts of root fragments, $\mathrm{A} \%$-arbuscules abundance in root system; yellow indicates positive correlation, dark red negative correlation, $p>0.05$ crossed.

\subsubsection{FT-IR Analysis}

In July 2017 (after nine months from planting) when plants entered summer dormancy, rhizome segments of similar age were collected from each experimental variant. Rhizomes were immediately peeled and aged by slow drying for a duration of 1.5 years (similar with the traditional method used for obtaining "white orris"). Voucher specimens are deposited at the Microbiology Department from Faculty of Agriculture UASVM Cluj-Napoca. Fourier transform infrared spectroscopy analysis was conducted in December 2018 at the Spectroscopy laboratory from Life Sciences Institute "King Michael I of Romania" from Cluj-Napoca. Pieces of dry and aged rhizomes were turned into powder using agate mortar and pestle. Then, calcinated $200 \mathrm{mg} \mathrm{KBr}$ was mixed with $3 \mathrm{mg}$ rhizome (orris) powder for each experimental variant and placed in spectral pellet press chamber steel kit. Vitrification of pellets was obtained using Specac hydraulic press by applying pressure of $10 \mathrm{t}$ for $2 \mathrm{~min}$. KBr pellet measurements were conducted with Fourier Transform Infrared Spectrometer Jasco FT/IR 4100, at scan range 4000-350 $\mathrm{cm}^{-1}$, accumulation 256 and resolution $4.0 \mathrm{~cm}^{-1}$. Spectra obtained was corrected for $\mathrm{CO}_{2}$ and $\mathrm{H}_{2} \mathrm{O}$ using Spectra Manager and further analysis conducted with Origin [35].

FT-IR spectra for rhizomes belonging to 12 experimental variants can be seen in Figure 4 . These spectra correspond to rhizomes from Iris germanica plants, which benefited from application of the commercial products with $\mathrm{AM}(\mathrm{AM}+)$ and control plants (AM-) of six cultivars. Changes that occurred for spectra refer to two types of characteristics: first, variations in peak position and secondly in peak intensity. These spectra features have been used before in FT-IR screening of rhizome samples belonging to Zingiberaceae species [36]. Shift in peak position refers to a displacement or change in peak wavenumber on FT-IR spectra for inoculated compared to non-inoculated plants of each cultivar, with a condition that the difference in positioning at either higher or lower wavenumber should be of at least 4 wavenumber units $\left(\mathrm{cm}^{-1}\right)$ and are marked on peak with a small pink or blue line (Figure 4). Increase or decrease in intensity is indicated by small arrows beneath bands screened for changes (Figure 4). In text when peak intensity changes are mentioned between non-inoculated versus inoculated plants, the values are provided, which represent how much the absorbance changed. Model peak analysis for two ranges proposed as marker bands for Iris germanica rhizome are detailed at the top of Figure 4, showing that contribution is given by different functional groups due to complex composition of rhizomes. List of peak readings for all 12 variants is provided in Supplementary Table S1. 


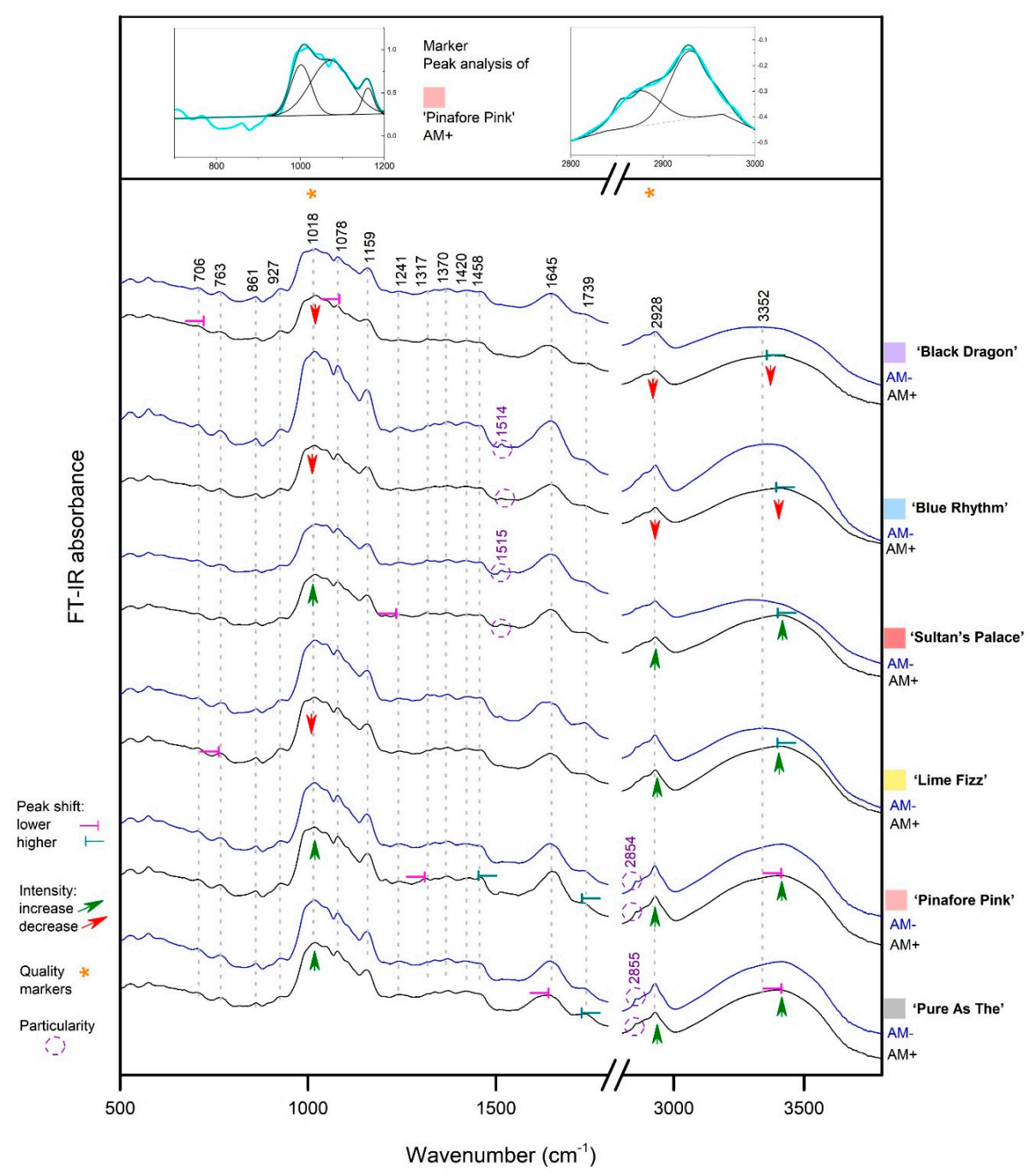

Figure 4. FT-IR spectra of rhizomes from non-inoculated (AM-) and inoculated (AM+) Iris germanica.

\section{Results and Discussion}

\subsection{Root AM Colonization}

In June 2017 and after 8 months from planting in the field, AM colonization was observed for both sets of plants: inoculated and not inoculated. Proliferation pattern corresponded to the Paris morphotype with cell-to-cell spreading of hyphae and lack of intercellular spreading. Correlation between colonization parameters can be seen in Figure 3.

Arbuscules had the aspect of dense intra-cellular coils (Figure 1f,g). Comparing the arbuscules abundance-as most important indicators of symbiose activity between plant and fungi-on average were higher for inoculated plants. Thus, AM arbuscules abundance in root system of Iris germanica increased from $\mathrm{A} \%=5.26$ in non-inoculated plants to $\mathrm{A} \%=7.14$ in inoculated plants. In relative values this change equals to increase in the root system of $35.7 \%$, while in mycorrhizal parts of root fragments (a\%) the increase was of only $0.79 \%$ compared to non-inoculated plants. This corresponds to the mode of action of the inoculation products: following application of the products with AM fungi, plant roots met a higher density of AM propagules, which opened a higher number of colonization sites on the root system. For both sets of plants an almost perfect correlation $\left(r^{2}=0.99\right)$ was found between intensity of colonization in roots fragments $(\mathrm{m} \%)$ and root system $(\mathrm{M} \%)$. A positive correlation was also found between these two intensity colonization indicators and arbuscules abundance in the root 
system for both sets of plants (Figure 3). Previous study reports that rhizomes of plants can also be colonized by AMF [37] but implications for plant are less clear.

\subsection{Rhizome FT-IR Spectra}

\subsubsection{Starch Presence in Rhizomes}

In Iris germanica, starch is the main reserve substance and accumulates in rhizome in high quantity, up to $50 \%$ [25]. Stored carbohydrate reserves in geophytes have influence on plant entrance in vegetation and is considered a quality marker due to direct influence on plant development [24]. An improved starch accumulation ensures adequate growth prior to flowering.

Starch possesses $\mathrm{OH}, \mathrm{C}-\mathrm{H}, \mathrm{C}-\mathrm{O}-\mathrm{C}$ and $\mathrm{C}-\mathrm{O}$ functional groups, which display typical peaks in FT-IR spectra across several ranges. Based on FT-IR analysis of starch from corn, cassava and potato [38], starch vibration modes in Iris germanica rhizome samples were also identified.

Thus, peaks between $763-770 \mathrm{~cm}^{-1}, 861-862 \mathrm{~cm}^{-1}$ and $925-928 \mathrm{~cm}^{-1}$ were characteristic to $\mathrm{C}-\mathrm{O}-\mathrm{C}$ ring vibration of starch molecule [38], while $\mathrm{C}-\mathrm{O}-\mathrm{C}$ asymmetric stretching vibration [38] was responsible for peaks occurring between $1154-1159 \mathrm{~cm}^{-1}$ in Iris germanica samples. Strong peaks from ranges 1016-1020 $\mathrm{cm}^{-1}$ and 1077-1078 $\mathrm{cm}^{-1}$ were caused by C-O stretching vibration from starch [38]. Within a similar range, presence of carbohydrates caused peaks found at $1077 \mathrm{~cm}^{-1}$ and $1146 \mathrm{~cm}^{-1}$ in Curcuma caesia rhizome [39], and at $1018 \mathrm{~cm}^{-1}$ in rhizome and roots of Panax ginseng [40].

Symmetric scissoring vibration of $\mathrm{CH}_{2}$ from starch molecule is responsible for peak from range $1416-1428 \mathrm{~cm}^{-1}$ of Iris germanica rhizome samples while symmetric deformation of same functional group [38] was causing the peak occurring between $1454-1458 \mathrm{~cm}^{-1}$ (Figure 4). The peak observed at $1639-1648 \mathrm{~cm}^{-1}$ was caused by $\mathrm{C}-\mathrm{O}$ bending vibration associated with $\mathrm{OH}$ group from starch as shown by previous authors [38]. Starch $\mathrm{C}-\mathrm{H}$ stretching vibration had a contribution to the band from $\approx 2930$ while O-H stretching from starch molecule had contribution to band from $\approx 3440$ [38], bands that were also present in Iris germanica rhizome samples (Figure 4).

Changes in relation with starch present in rhizome should be indicated by changes in position and intensity of characteristic peaks for starch identified. Rhizome samples of Iris germanica 'Pinafore Pink' from plants which benefited from AM products at planting presented increased intensity (with 0.15-0.41 absorbance increase) for typical starch peaks situated in the range identified above as well as for the two broad bands between $2800-3600 \mathrm{~cm}^{-1}$. Similarly, Iris germanica 'Pure As The' also presented increase in peak intensity (with $0.01-0.23$ absorbance increase) for all typical starch peaks with the exception of peak situated between $1639-1644 \mathrm{~cm}^{-1}$. Samples from 'Sultan's Palace' and 'Lime Fizz' $\mathrm{AM}+$ plants, presented an increase in band intensity for the two broad bands situated between 2800 and $3600 \mathrm{~cm}^{-1}$ to which starch vibration modes also had a contribution but not for all the other typical peaks. Based on these it was concluded that products with AM applied could have favored starch accumulation in rhizomes of 'Pinafore Pink' and to some degree to 'Pure As The'. Previous studies in relation with effect of AM application on plant composition suggest that changes are due to improved nutrition following colonization [21]. This effect was not identified in all cultivars. An explanation could be the existence of specificity, which controls the outcome of AMF-plant interaction, as it was demonstrated for several medicinal plants, or changes might not be detectable [21]. In this regard, specific metabolite accumulation was conditioned by fungi species in Salvia sp. [41] and Zingiber sp. [42] and by cultivar for Mentha sp. [43]. The potential to increase starch accumulation and maximize beneficial effects for plant requires the identification and selection of genotypes, which exhibit the best response to AM inoculation in field.

\subsubsection{Myristic Acid in Rhizomes}

Myristic acid is the most abundant fatty acid in the Iris germanica rhizome [25], and is responsible for butter consistency of the commercial extract obtained from rhizomes [2]. It can be isolated and be 
used as raw material in the beauty industry [44], while methyl and ethyl esters of myristic acid are used as blenders in violet type perfume bases [45].

Typically, FT-IR myristic acid spectra shows distinctive peaks at $2848 \mathrm{~cm}^{-1}$ and $2916 \mathrm{~cm}^{-1}$ due to symmetrical and respectively asymmetrical stretching of $\mathrm{CH}_{2}$, as well as $-\mathrm{OH}$ swinging or rocking vibrations within the range $680-940 \mathrm{~cm}^{-1}$ due to aliphatic chain [46] but have weaker intensity. In Iris germanica samples, peaks position from $\approx 2900 \mathrm{~cm}^{-1}$ did not vary among cultivars but were situated at a higher wavenumber. The first one, was situated at $2855 \mathrm{~cm}^{-1}$ and appeared more distinctive for 'Pinafore Pink' and 'Pure As The', which could indicate to a genotype particularity. The second one occurring in the spectral range $2926-2928 \mathrm{~cm}^{-1}$ showed an increase intensity in samples from AM inoculated plants belonging to four cultivars, with exception of 'Black Dragon' and 'Blue Rhythm'. Intensity change corresponded to a $0.12-0.37$ absorbance increase. In a similar range, signal attributed to fatty acids was identified for Curcuma caesia rhizome samples at $2924 \mathrm{~cm}^{-1}$ [39], for rhizomes and roots of Panax ginseng at $2923 \mathrm{~cm}^{-1}$ [40] and in Curcuma longa rhizomes at $2925 \mathrm{~cm}^{-1}$ [47].

\subsubsection{Other Metabolites in Rhizomes}

Presence of other major compounds in Iris germanica rhizomes was confirmed by comparison with previous studies conducted on geophyte plants.

A pervious study on roots of Iris germanica has put in evidence a distinctive peak at $1510 \mathrm{~cm}^{-1}$ assigned to vibrations of molecular bounds from aromatic structure of lignin, which is less sensitive to IR and as consequence presents a weak intensity [48]. In rhizomes of Iris germanica this peak occurred between 1509 and $1516 \mathrm{~cm}^{-1}$ and also has weak intensity. Interestingly, this peak is more distinguishable in samples of 'Blue Rhythm' and 'Sultan's Palace' compared to other cultivars regardless of treatment, which could indicate to higher lignification of rhizome as the genotype characteristic. Lignin is essential for structural integrity of cell walls of vascular plants but is also a first line in defense against pathogens, lignification being linked to disease residence in plants [49]. Soft rot is a very widespread disease of cultivated Iris [1] and genotypes displaying this characteristic might prove helpful in breeding improved ornamental irises with rot-resistance. This aspect could be a premise for investigation in the future.

Phenols and proteins presence in rhizome could also be confirmed. Thus, the peak occurring within range $1369-1372 \mathrm{~cm}^{-1}$ of Iris germanica samples, could be attributed to phenols, similar peak being identified previously in the Valeriana wallichii root at $1373.32 \mathrm{~cm}^{-1}$ due to C-O stretching vibrations [50]. The peak found between $1639-1648 \mathrm{~cm}^{-1}$ in Iris germanica rhizomes indicates to the presence of proteins as assigned by previous studies conducted on Curcuma longa rhizomes with the peak corresponding to amide I displayed at $1644 \mathrm{~cm}^{-1}$ [47], and at $1640 \mathrm{~cm}^{-1}$ or $1635 \mathrm{~cm}^{-1}$ in Curcuma caesia rhizome [39,51].

Broad band between 3000 and $3600 \mathrm{~cm}^{-1}$ showed high variation among cultivars for peak position, which situated between 3352 and $3417 \mathrm{~cm}^{-1}$. For rhizome sample belonging to AM inoculated plants, it is noticeable an increase of overall band intensity in four cultivars. Vibrations of molecular bounds from several compounds contribute to this band [39,40]. However, previous authors, after studying Iris germanica root cells made the observation that a reduced protein content in sample results in a decrease of band intensity at $3320 \mathrm{~cm}^{-1}$ [48]. Similarly, band between 1000 and $1200 \mathrm{~cm}^{-1}$ besides the starch vibration modes already discussed, a contribution is made also by the $\mathrm{CH}_{3}$ functional group [51] from the structure of cellulose [39].

Vibration modes of different functional groups give arise to several peaks of weaker intensity. The peak occurring at $702-706 \mathrm{~cm}^{-1}$ in all Iris germanica rhizome samples are due to the vibration of molecular bounds from aromatic ring, as indicated by studies on rhizomes of Polygonum cuspidatum [52] and Hedychium coronarium [53]. Peak situated between 1240 and $1246 \mathrm{~cm}^{-1}$ from Iris germanica samples can be attributed to C-O stretching vibrations, similarly described for Valeriana wallichii roots [50], while the one between 1311 and $1319 \mathrm{~cm}^{-1}$ to the $\mathrm{C}-\mathrm{H}$ functional group as identified in the Curcuma caesia rhizome [51]. The peak between 1730 and $1745 \mathrm{~cm}^{-1}$ in Iris germanica rhizomes could be attributed 
to $\mathrm{C}=\mathrm{O}$ stretching vibration, with peaks in similar range identified before in Iris germanica roots [48], rhizomes from species Curcuma longa, Curcuma xanthorrhiza, Zingiber cassumunar [36] and underground plant parts of Panax ginseng [40].

\subsubsection{Significance of the Findings}

Using FT-IR analysis to screen Iris germanica rhizome samples collected after nine months from AM application, presence of main compounds from rhizome was confirmed, as well as potential to improve quality for certain cultivars. Previous study showed that enhancement of secondary metabolites in licorice roots due to AM inoculation became evident after six months [54].

On an effect scale, 'Pinafore Pink' seemed to present favorable response, followed by 'Pure As The'. Interestingly, as showed in previous works regarding vegetative [27] and physiological [28] parameters of these plants, emerges a similar pattern.

Difference due to the genotype response could be explained by referring to the genetic background of these tetraploid cultivated hybrids. Modern traits such as wide and ruffled petals controlled by recessive genes [1] can be admired in the more recent garden Iris category and it is the case for cultivars with red, pink, yellow and white flowers from this study. Intensification of color observed in the black-flowered cultivars of today is credited to genetic contribution of a wild species with dark flowers [1] thus, setting apart the cultivar 'Black Dragon' from the others. From cultivars studied here, oldest one is 'Blue Rhythm' [55], which could be considered closely related to historic cultivated forms since it lacks modern flower traits. Based on these it is suggested that genetic background might set apart cultivars also in terms of response to commercial AM products.

Previous authors remarked the current practical necessity of more AM experiments in the field and voiced existing difficulties in drawing clear evidence as prerequisite in justifying certain direction for agronomic practice [56]. Thus, experiments in real-life conditions can address practical challenges related to efficiency of microbial inoculants in agriculture.

\section{Conclusions}

FT-IR is a suitable technique for comparative characterization of plant constituents. Presence of main Iris germanica metabolites can be confirmed based on spectra analysis, including for rhizome quality markers such as carbohydrates and fatty acids.

Results suggest that application of commercial products with AM could enhance accumulation of starch and myristic acid in rhizome of certain cultivars such as 'Pinafore Pink'. Thus, commercial products with AM could have a positive influence both on plant development as well as on extractable compounds.

Supplementary Materials: The following are available online at http://www.mdpi.com/2073-4395/9/12/815/s1, Table S1: FT-IR peak values for the 12 variants.

Author Contributions: I.C., R.V. conceptualization; I.C., V.S. methodology; I.C. investigation (microscopy) and formal analysis; I.C., L.O., R.S. investigation (FT-IR analysis); I.C. writing — original draft preparation; R.V., R.Ş., L.O., V.S., A.M. writing-review and editing.

Funding: This research received no external funding.

Acknowledgments: Authors are thankful to Ioana Moldovan from “Horticultural Research Station” Cluj for help at planting.

Conflicts of Interest: The authors declare no conflict of interests.

\section{References}

1. Crișan, I.; Vidican, R.; Stoian, V.; Stoie, A. Wild Iris spp. from Romanian meadows and their importance for ornamental plant breeding. Rom. J. Grassl. Forage Crops 2017, 16, 21-32.

2. Crisan, I.; Cantor, M. New perspectives on medicinal properties and uses of Iris sp. Hop Med. Plant. 2016, 24, 24-36. 
3. Lim, T.K. Iris x germanica. In Edible Medicinal and Non-medicinal Plants; Modified stems, roots and bulbs; Springer: Cham, Switzerland, 2016; Volume 11, pp. 27-40. [CrossRef]

4. Kara, N.; Gürbüzer, G. Effect of harvest times on rhizoma yield, essential oil content and composition in Iris germanica L. species. TURJAF 2019, 7, 707-713. [CrossRef]

5. DeBaggio, T.; Tucker, A.O. The Encyclopedia of Herbs: A Comprehensive Reference to Herbs of Flavor and Fragrance; Timber Press: Portland, ME, USA, 2009.

6. Belletti, G.; Fani, E.; Marescotti, A.; Scaramuzzi, S. The role of traditional products in the valorisation of marginal rural areas: The case of Iris pallida. SJAR 2013, 4, 11-23. [CrossRef]

7. Firmin, L.; Courtois, D.; Pétiard, V.; Ehret, C.; Lerch, K. Evaluation of the natural variability in irone content and selection of Iris sp. for perfume production. HortScience 1998, 33, 1046-1047. [CrossRef]

8. Roger, B.; Fernandez, X.; Jeannot, V.; Chahboun, J. An alternative method for irones quantification in iris rhizomes using headspace solid-phase microextraction. Phytochem. Anal. 2010, 21, 483-488. [CrossRef]

9. Price of Orris Butter. Available online: https:/hermitageoils.com/product/orris-butter-essential-oil-13-irones/ (accessed on 26 August 2019).

10. Meyer, C.J.; Peterson, C.A.; Steudle, E. Permeability of Iris germanica's multiseriate exodermis to water, $\mathrm{NaCl}$, and ethanol. J. Exp. Bot. 2011, 62, 1911-1926. [CrossRef]

11. Lamaoui, M.; Jemo, M.; Datla, R.; Bekkaoui, F. Heat and drought stresses in crops and approaches for their mitigation. Front. Chem. 2018, 6, 26. [CrossRef]

12. Engel, R.; Szabo, K.; Abranko, L.; Rendes, K.; Füzy, A.; Takács, T. Effect of arbuscular mycorrhizal fungi on the growth and polyphenol profile of marjoram, lemon balm, and marigold. J. Agric. Food Chem. 2016, 64, 3733-3742. [CrossRef]

13. Scagel, C.F.; Lee, J. Phenolic composition of basil plants is differentially altered by plant nutrient status and inoculation with mycorrhizal fungi. HortScience 2012, 47, 660-671. [CrossRef]

14. Schweiger, R.; Mueller, C. Leaf metabolome in arbuscular mycorrhizal symbiosis. Curr. Opin. Plant Biol. 2015, 26, 120-126. [CrossRef] [PubMed]

15. Zeng, Y.; Guo, L.-P.; Chen, B.-D.; Hao, Z.-P.; Wang, J.-Y.; Huang, L.-Q.; Yang, G.; Cui, X.-M.; Yang, L.; Wu, Z.-X. Arbuscular mycorrhizal symbiosis and active ingredients of medicinal plants: Current research status and prospectives. Mycorrhiza 2013, 23, 253-265. [CrossRef] [PubMed]

16. Pedone-Bonfim, M.V.L.; da Silva, F.S.B.; Maia, L.C. Production of secondary metabolites by mycorrhizal plants with medicinal or nutritional potential. Acta Physiol. Plant. 2015, 37, 27. [CrossRef]

17. Dutta, S.C.; Neog, B. Accumulation of secondary metabolites in response to antioxidant activity of turmeric rhizomes co-inoculated with native arbuscular mycorrhizal fungi and plant growth promoting rhizobacteria. Sci. Hortic. 2016, 204, 179-184. [CrossRef]

18. Raghuwanshi, R.; Sinha, S. Linking mycorrhizal technology with medicinal plant secondary metabolites. In Microbial Diversity and Biotechnology in Food Security; Springer: New Dehli, India, 2014; pp. 121-132.

19. Zhang, H.; Sun, J.; Bao, Y. Advances in studies on plant secondary metabolites influenced by arbuscular mycorrhizal fungi. J. Agric. biotechnol. 2015, 23, 1093-1103.

20. Kilam, D.; Sharma, P.; Agnihotri, A.; Kharkwal, A.; Varma, A. Microbial symbiosis and bioactive ingredients of medicinal plants. In Mycorrhiza-eco-physiology, Secondary Metabolites, Nanomaterials; Springer: Cham, Switzerland, 2017; pp. 283-302.

21. Crișan, I.; Vidican, R.; Stoian, V. Induced modifications on secondary metabolism of aromatic and medicinal plants-an endomycorrhizal approach. Hop Med. Plant. 2018, 26, 15-29.

22. Kosa, G.; Shapaval, V.; Kohler, A.; Zimmermann, B. FTIR spectroscopy as a unified method for simultaneous analysis of intra-and extracellular metabolites in high-throughput screening of microbial bioprocesses. Microb. Cell Fact. 2017, 16, 195. [CrossRef]

23. Ţucureanu, V.; Matei, A.; Avram, A.M. FTIR Spectroscopy for Carbon Family Study. Crit. Rev. Anal. Chem. 2016, 46, 502-520. [CrossRef]

24. Ciobanu, I.; Cantor, M.; Stefan, R.; Erzsebet, B.; Magyari, K.; Monica, B. The influence of storage conditions on the biochemical composition and morphology of dahlia tubers. Not. Bot. Horti Agrobo. Cluj-Napoc. 2016, 44, 459-465. [CrossRef]

25. Robu, T. A Monograph of Genus Iris; Ion Ionescu de la Brad: Iași, Romania, 2005; ISBN 973-7921-60-7.

26. Davidescu, D.; Calancea, L.; Davidescu, V.; Lixandru, G.; Țârdea, C. Agrochimie; Editura Didactică și Pedagogică: Bucharest, Romania, 1981. 
27. Crișan, I.; Vidican, R.; Stoian, V.; Cantor, M. The effects of supplementary mycorrhization regarding some vegetative characteristics at iris germanica L. Lucrări Științifice Seria Agronomie USAMV Iași 2017, 60, $209-214$.

28. Crișan, I.; Vidican, R.; Stoian, V.; Vâtcă, S.; Stoie, A. Leaf stomatal parameters of Iris germanica L. influenced by cultivar and arbuscular mycorrhizae inoculation in field conditions, Romania. Sci. Papers Series B Hortic. 2018, 62, 619-628.

29. Weather Cluj-Napoca. Available online: https://www.wunderground.com/history/daily/ro/cluj-napoca/LRCL (accessed on 21 May 2019).

30. Root Grow AMF. Available online: http://rootgrow.co.uk/ (accessed on 22 November 2019).

31. Vierheilig, H.; Coughlan, A.P.; Wyss, U.R.S.; Piché, Y. Ink and vinegar, a simple staining technique for arbuscular-mycorrhizal fungi. Appl. Environ. Microbiol. 1998, 64, 5004-5007. [PubMed]

32. Lab Procedures, Trouvelot Method. Available online: https://www2.dijon.inra.fr/mychintec/Protocole/ Workshop_Procedures.html\#1.5 (accessed on 21 May 2019).

33. Mycocalc Software; Institut National de la Recherche Agronomique. Available online: https://www2.dijon. inra.fr/mychintec/Mycocalc-prg/download.html (accessed on 21 May 2019).

34. Hammer, Ø. Past 3.x Software; Natural History Museum, University of Oslo. Available online: https: //folk.uio.no/ohammer/past/ (accessed on 28 November 2019).

35. Origin: Data Analysis and Graphing Software; Origin Lab. Available online: https://www.originlab.com/ (accessed on 28 November 2019).

36. Rohaeti, E.; Rafi, M.; Syafitri, U.D.; Heryanto, R. Fourier transform infrared spectroscopy combined with chemometrics for discrimination of Curcuma longa, Curcuma xanthorrhiza and Zingiber cassumunar. Spectrochim. Acta A 2015, 137, 1244-1249. [CrossRef] [PubMed]

37. Taber, R.A.; Trappe, J.M. Vesicular-arbuscular mycorrhiza in rhizomes, scale-like leaves, roots, and xylem of ginger. Mycologia 1982, 74, 156-161. [CrossRef]

38. Abdullah, A.H.D.; Chalimah, S.; Primadona, I.; Hanantyo, M.H.G. Physical and chemical properties of corn, cassava, and potato starch. IOP Conf. Ser. Earth Environ. Sci. 2018, 160, 012003. [CrossRef]

39. Sharma, N.; Khajuria, Y.; Sharma, J.; Gondal, M.A.; Kumar, V.; Dwivedi, Y.; Singh, V.K. Spectroscopic analysis of rhizomes of black turmeric (Curcuma caesia). In Proceedings of the AIP Conference Proceedings, Jammu, India, 17-18 April 2018; AIP Publishing: New York, NY, USA, 2018; pp. 030036-1-030036-6. [CrossRef]

40. Lee, B.-J.; Kim, H.-Y.; Lim, S.R.; Huang, L.; Choi, H.-K. Discrimination and prediction of cultivation age and parts of Panax ginseng by Fourier-transform infrared spectroscopy combined with multivariate statistical analysis. PLoS ONE 2017, 12, e0186664. [CrossRef]

41. Yang, Y.; Ou, X.; Yang, G.; Xia, Y.; Chen, M.; Guo, L.; Liu, D. Arbuscular Mycorrhizal Fungi Regulate the Growth and Phyto-Active Compound of Salvia miltiorrhiza Seedlings. Appl. Sci. 2017, 7, 68. [CrossRef]

42. da Silva, M.F.; Pescador, R.; Rebelo, R.A.; Stürmer, S.L. The effect of arbuscular mycorrhizal fungal isolates on the development and oleoresin production of micropropagated Zingiber officinale. Braz. J. Plant Physiol. 2008, 20, 119-130. [CrossRef]

43. Gupta, M.L.; Prasad, A.; Ram, M.; Kumar, S. Effect of the vesicular-arbuscular mycorrhizal (VAM) fungus Glomus fasciculatum on the essential oil yield related characters and nutrient acquisition in the crops of different cultivars of menthol mint (Mentha arvensis) under field conditions. Bioresour. Technol. 2002, 81, 77-79. [CrossRef]

44. Myristic Acid. Available online: https://www.makingcosmetics.com/Myristic-Acid_p_1045.html?locale=en (accessed on 22 November 2019).

45. Arctander, S. Perfume and Flavor Materials of Natural Origin; Lulu Press Inc: Morrisville, NC, USA, $2017 ;$ p. 358.

46. Trivedi, M.K.; Tallapragada, R.M.; Branton, A.; Trivedi, D.; Nayak, G.; Mishra, R.K.; Snehasis, J. Physical, spectroscopic and thermal characterization of biofield treated myristic acid. J. Fundam. Renew. Energy Appl. 2015, 5, 3-6. [CrossRef]

47. Nille, G.C.; Singh, V.K.; Reddy, K. Investigation of Talapotaka Churna using FTIR spectroscopy. JAHM 2016, 4, 3-11.

48. Zeier, J.; Schreiber, L. Fourier transform infrared-spectroscopic characterisation of isolated endodermal cell walls from plant roots: Chemical nature in relation to anatomical development. Planta 1999, 209, 537-542. [CrossRef] [PubMed]

49. Bhuiyan, N.H.; Selvaraj, G.; Wei, Y.; King, J. Role of lignification in plant defense. Plant Signal. Behav. 2009, 4, 158-159. [CrossRef] [PubMed] 
50. Sahu, V.; Dhongade, H.J.; Sawarkar, H.A.; Sahu, P.; Sahu, R.; Patel, D.; Kashyap, P. Isolation and characterization of valerenic acid from Valeriana wallichii (Valerianaceae). IJBPAS 2016, 5, 1230-1243.

51. Pakkirisamy, M.; Kalakandan, S.K.; Ravichandran, K. Phytochemical screening, GC-MS, FT-IR analysis of methanolic extract of Curcuma caesia Roxb (Black Turmeric). Pharmacogn. J. 2017, 9. [CrossRef]

52. Ardelean, F.; Moaca, E.A.; Pacurariu, C.; Antal, D.S.; Dehelean, C.; Toma, C.-C.; Dragan, S. Invasive Polygonum cuspidatum: Physico-chemical analysis of a plant extract with pharmaceutical potential. Studia Universitatis" Vasile Goldis" Arad. Seria Stiintele Vietii (Life Sciences Series) 2016, 26, 415.

53. Pachurekar, P.; Dixit, A.K. Phytochemical screening and spectroscopic characterization of phytoconstituents from rhizome extract of Hedychium coronarium J. Koenig. Int. J. Res. BioSci. 2018, 7, 34-40. [CrossRef]

54. Orujei, Y.; Shabani, L.; Sharifi-Tehrani, M. Induction of glycyrrhizin and total phenolic compound production in licorice by using arbuscular mycorrhizal fungi. Russ. J. Plant Physiol. 2013, 60, 855-860. [CrossRef]

55. Irises: Plant Care and Collection of Varieties. Available online: https:/garden.org/plants/group/irises/ (accessed on 10 September 2019).

56. Ryan, M.H.; Graham, J.H. Little evidence that farmers should consider abundance or diversity of arbuscular mycorrhizal fungi when managing crops. New Phytol. 2018, 220, 1092-1107. [CrossRef]

(C) 2019 by the authors. Licensee MDPI, Basel, Switzerland. This article is an open access article distributed under the terms and conditions of the Creative Commons Attribution (CC BY) license (http://creativecommons.org/licenses/by/4.0/). 